\title{
MICROWAVE FUSION OF A LOW-FUSING TITANIUM BODY PORCELAIN COATING DERIVED FROM FACILE SOL-GEL COMBUSTION SYNTHESIS
}

\author{
QIXUAN WANG, XUEMEI LIU, " LITONG GUO, "XUEYU TAO, JIAXI MENG, XUANRU REN, ZHONGXUAN \\ ZHANG, ZHANGSHENG LIU
}

\author{
School of Materials Science \& Engineering, China University of Mining and Technology,
} Xuzhou 221116, P.R. China

\#E-mail: litongguo@cumt.edu.cn, taoxueyu@iccas.ac.cn

Submitted February 5, 2019; accepted March 18, 2019

\begin{abstract}
Keywords: Sol-gel preparation, Combustion, Bio-ceramics, Titanium, Body porcelain
Titanium body porcelains were synthesised through the sol-gel combustion method by using carbamide and glycine as the composite organic fuels with a mole ratio of 7:3. Then the synthesised porcelain was microwave fused on the Ti surface. The porcelain was characterised by X-ray diffraction and scanning electron microscope tests. The XRD results showed that the body porcelains ignited at 400, 500 and $600{ }^{\circ} \mathrm{C}$ were all amorphous. When the ignited temperature is only $400{ }^{\circ} \mathrm{C}$, some crystalline diffraction peaks of $\mathrm{KNO}_{3}$ existed due to the incomplete combustion reaction. When the igniting temperature was elevated to 500 and $600{ }^{\circ} \mathrm{C}$ or a higher ratio of fuel to nitrates (1.25:1 and 1.5:1) was employed, the nitrates completely reacted and there was no obvious nitrate residue. The size and quantity of the pores slightly increased with the ratio of fuel to nitrates increased from 1:1 to 1.5:1. A dense coating with a homogeneous vitreous structure was fused on the Ti surface by microwaves.
\end{abstract}

\section{INTRODUCTION}

Titanium has received much more attention as a good dental restorative material, because of its excellent characteristics, such as low cost, high strength, being lightweight, having excellent corrosion resistance and biocompatibility [1-3]. However, when the fusion temperature is above $800{ }^{\circ} \mathrm{C}$, the Ti surface oxidation will result in a decrease in the bonding strength between the porcelain and $\mathrm{Ti}$, which restricts the application of titanium porcelain [4-6]. Therefore, a special titanium body porcelain with low fusion temperature was developed in this research.

The conventional melting-quenching manufacturing process has been used to produce porcelain powders [7]. The porcelains synthesised by the sol-gel combustion method have a higher sintering activity and lower sintering temperature, for its rational utilisation of the liberated energy from the high exothermic reaction of the fuels and oxidants [8,9]. Sol-gel combustion synthesis and microwave sintering can both reduce the synthetic and sintering temperature as ways of rapid synthetic methods [10, 11], which will avoid bonding strength degradation caused by excessive oxidation of the titanium surface. Therefore, the research was focused on the sol-gel combustion synthesis and microwave fusion processing to prepare an amorphous body porcelain layer on Ti with a fine-grained microstructure [12].

\section{EXPERIMENTAL}

The body porcelain with the weight percent composition of $69 \% \mathrm{SiO}_{2}-6 \% \mathrm{Na}_{2} \mathrm{O}-5 \% \mathrm{~K}_{2} \mathrm{O}-2 \%$ $\mathrm{Li}_{2} \mathrm{O}-6 \% \mathrm{CaO}-4 \% \mathrm{~B}_{2} \mathrm{O}_{3}-7 \% \mathrm{Al}_{2} \mathrm{O}_{3}-1 \% \mathrm{ZnO}$ was synthesised by sol-gel processing as in our previous work [12]. Carbamide and glycine were used as the composite organic fuels with a mole ratio of 7:3. The composite organic fuels were added into the solution at different fuels to nitrates ratios, such as 1:1, 1.25:1 and 1.5:1, and stirred continuously until they were completely dissolved. A homogeneous gel was obtained after $4 \mathrm{~h}$ of stirring and 3 days of ageing at $60{ }^{\circ} \mathrm{C}$. Then the xerogel was ground with an alumina crucible and ignited at different temperatures in a furnace to finish the combustion synthesis. The prepared porcelain was deposited on the surface of the Ti substrate by spincoating processing and then dried in the oven at $60^{\circ} \mathrm{C}$ for $30 \mathrm{~min}$. Then the synthesised porcelain coating was microwave fused on the Ti surface with a heating rate of $80{ }^{\circ} \mathrm{C} / \mathrm{min}$ and holding for $20 \mathrm{~min}$ at the sintering temperature in the microwave furnace (MobileLab Workstation, Tangshan Nayuan microwave thermal in-strument manufacturing co., LTD.). The porcelain powders were examined by an X-ray diffractometer (D/max-r, Rigaku Corp., Japan) and a Field-Emission Scanning Electron Microscope (SU8220, HITACHI, Japan). 


\section{RESULT AND DISCUSSION}

Figure 1 shows the XRD patterns of body porcelains ignited at different temperatures. The XRD results demonstrated that all the three body porcelains mainly showed steamed bead peaks, indicating that their major phases were amorphous. When the igniting temperature is only $400{ }^{\circ} \mathrm{C}$, some crystalline diffraction peaks of $\mathrm{KNO}_{3}$ (JCPDS: 32-0824) existed, which represented that the fuels were not adequate enough to react with the oxidant of the nitrates. The chemical reaction equations between the nitrate and carbamide are shown as below. Similar equations are shown for the glycine. In addition, it may be due to the incomplete combustion resulting from the lower ignition temperature and the incomplete decomposition of nitrates. Therefore, excessive fuels with a fuel to nitrates ratio of 1.25:1 and 1.5:1 were used and the effect of the fuel to nitrates ratio on the crystal structure of the porcelains was studied.

$$
\begin{aligned}
& 3 \mathrm{Ca}\left(\mathrm{NO}_{3}\right)_{2}+5 \mathrm{CO}\left(\mathrm{NH}_{2}\right)_{2} \rightarrow \\
& \rightarrow 3 \mathrm{CaO}+10 \mathrm{H}_{2} \mathrm{O} \uparrow+8 \mathrm{~N}_{2} \uparrow+5 \mathrm{CO}_{2} \uparrow \\
& 6 \mathrm{NaNO}_{3}+5 \mathrm{CO}\left(\mathrm{NH}_{2}\right)_{2} \rightarrow \\
& \rightarrow 3 \mathrm{Na}_{2} \mathrm{O}+10 \mathrm{H}_{2} \mathrm{O} \uparrow+8 \mathrm{~N}_{2} \uparrow+5 \mathrm{CO}_{2} \uparrow \\
& 6 \mathrm{KNO}_{3}+5 \mathrm{CO}\left(\mathrm{NH}_{2}\right)_{2} \rightarrow \\
& \rightarrow 3 \mathrm{~K}_{2} \mathrm{O}+10 \mathrm{H}_{2} \mathrm{O} \uparrow+8 \mathrm{~N}_{2} \uparrow+5 \mathrm{CO}_{2} \uparrow
\end{aligned}
$$

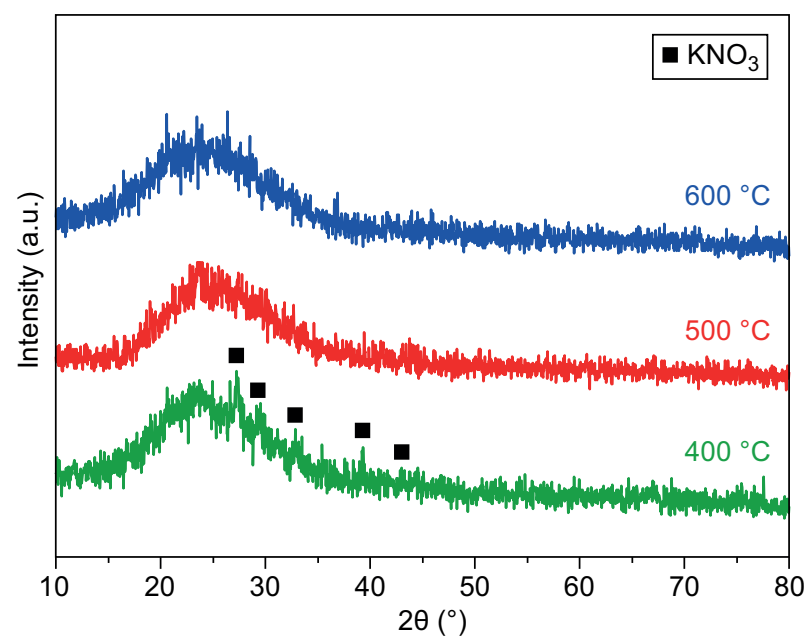

Figure 1. The XRD patterns of the body porcelains ignited at 400,500 and $600{ }^{\circ} \mathrm{C}$ with a fuel to nitrates ratio of $1: 1$.

Figure 2 shows the XRD patterns of porcelains ignited at $400^{\circ} \mathrm{C}$ with the fuel to nitrates ratio of $1: 1,1.25: 1$ and 1.5:1. The XRD results demonstrated that when the fuel to nitrates ratio increased to $1.25: 1$ and 1.5:1, both of the body porcelains exhibited an amorphous structure, indicating the adequate reaction of $\mathrm{KNO}_{3}$. As the molar ratio $\mathrm{R}$ increases, the residual $\mathrm{KNO}_{3}$ crystal fades away gradually. The increase of the fuel quantity contributes to the higher reaction temperature, where the nitrate can be broken down adequately. Therefore, we can know that the increase in the fuel quantity makes up for the influence of the inefficient ignition temperature. As a result, no diffraction peaks of $\mathrm{KNO}_{3}$ were found and a homogeneous amorphous structure was obtained.

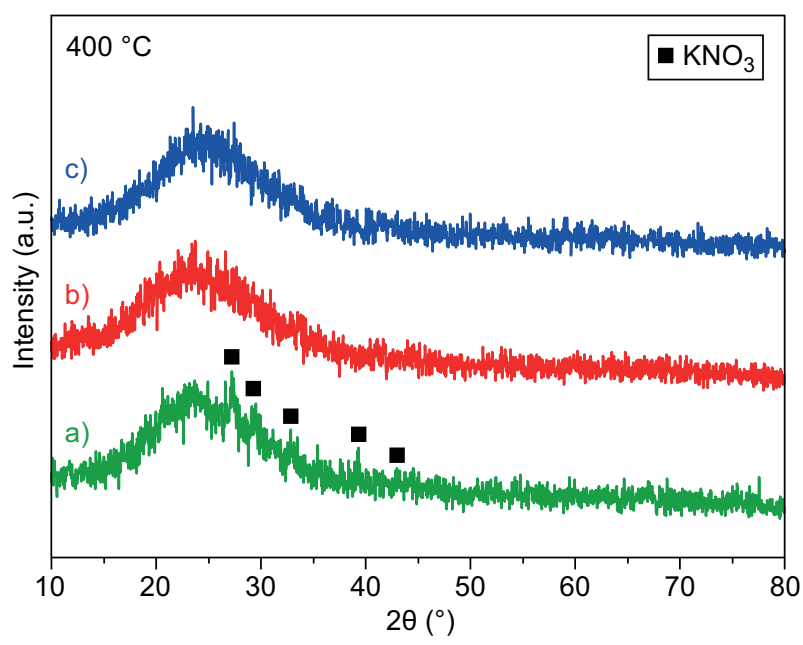

Figure 2. The XRD patterns of the titanium body porcelains ignited at $400{ }^{\circ} \mathrm{C}$ with a fuel to nitrates ratio of: a) $1: 1$, b) $1.25: 1$ and c) $1.5: 1$.

Figure 3 shows the XRD patterns of the titanium body porcelains ignited at $500{ }^{\circ} \mathrm{C}$ with the fuel to nitrates ratio of (a) 1:1, (b) 1.25:1 and (c) 1.5:1. Similar to Figure 2, the major phase of all three body porcelains were amorphous and no crystalline diffraction peaks of $\mathrm{KNO}_{3}$ existed, which represented that the fuels adequately reacted with the oxidant of the nitrates. When the igniting temperature increased to $500{ }^{\circ} \mathrm{C}$, the increase in the fuel quantity scarcely affected the crystal-structure of the porcelains.

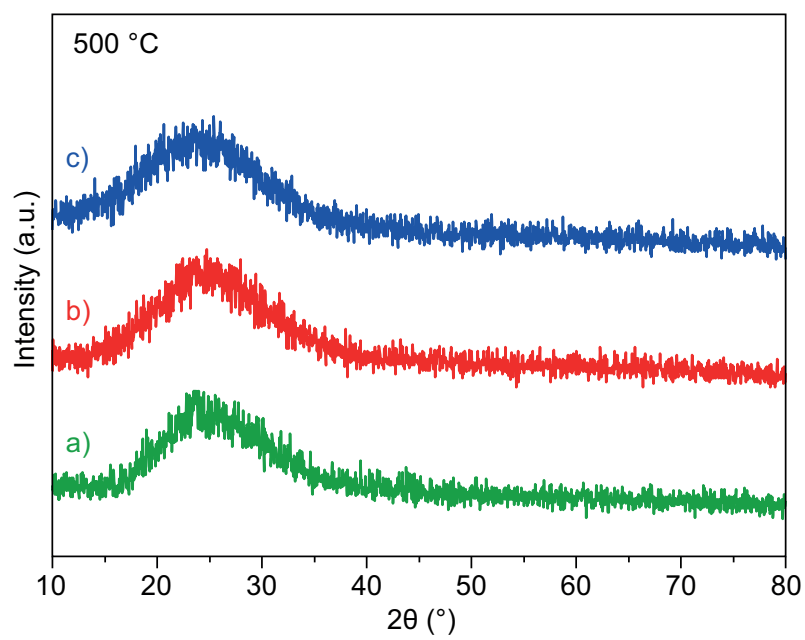

Figure 3. The XRD patterns of the titanium body porcelains ignited at $500{ }^{\circ} \mathrm{C}$ with a fuel to nitrates ratio of: a) $1: 1$, b) $1.25: 1$ and c) $1.5: 1$. 
Wang Q., Liu X., Guo L., Tao X., Meng J., Ren X., Zhang Z., Liu Z.

The SEM microphotographs of the porcelain particles are shown in Figure 4. Figure 4a shows that the porcelain particles sizes ranged from about $10 \mu \mathrm{m}$ to $80 \mu \mathrm{m}$ and $\mathrm{D}_{50}$ was $28.64 \mu \mathrm{m}$. Figure $4 \mathrm{~b}$ shows that there were scarcely any pores formed on the body porcelain surface. Figure $4 \mathrm{c}$ shows that the porcelain particles sizes ranged from about $10 \mu \mathrm{m}$ to $100 \mu \mathrm{m}$ and $\mathrm{D}_{50}$ was $41.33 \mu \mathrm{m}$. Figure $4 \mathrm{~d}$ shows that there were many pores on the porcelain surface (the pore size ranged from about $200 \mathrm{~nm}$ to $1.4 \mu \mathrm{m}$ ). Figures $4 \mathrm{e}$ and $\mathrm{f}$ show similar particle structures to $\mathrm{c}$ and $\mathrm{d}$, while the pore sizes ranged from about $200 \mathrm{~nm}$ to $2.4 \mu \mathrm{m}$. When the fuel to nitrates ratio increased from $1: 1$ to $1.5: 1$, the size and quantity of the pores slightly increased.

The TEM, the selected area electron diffraction (SAED) and the EDS photographs of the porcelain particles are shown in Figure 5. Figure 5a shows that the shape of the porcelain particle was irregular and its size was about $5 \mu \mathrm{m}$ long and $4 \mu \mathrm{m}$ wide. The SAED photograph in Figure $5 \mathrm{~b}$ indicated the phase of the

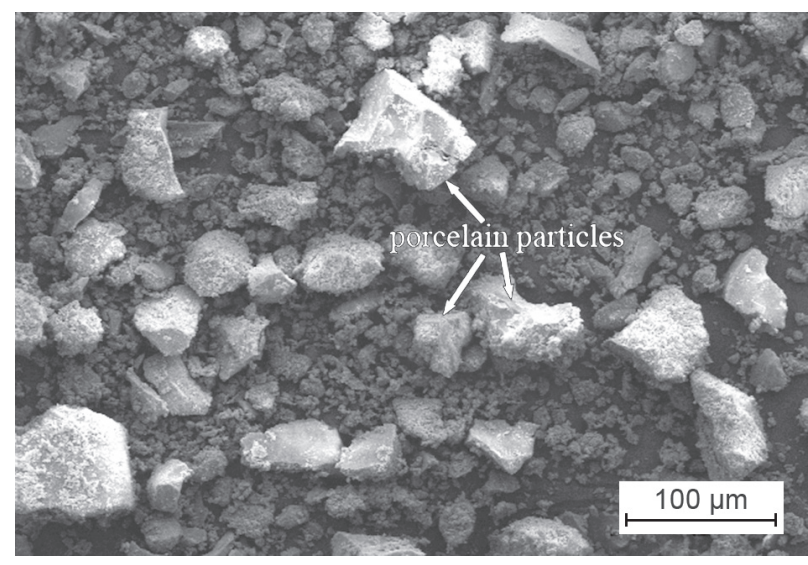

a) $1: 1$

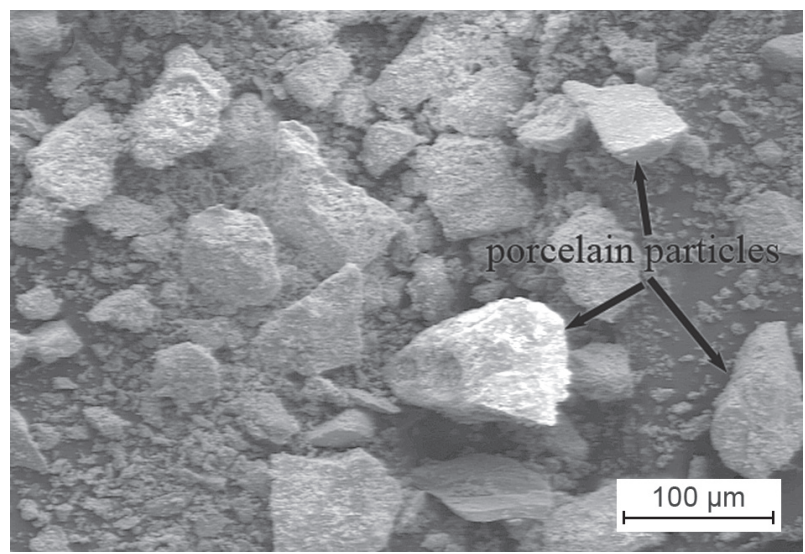

c) $1.25: 1$

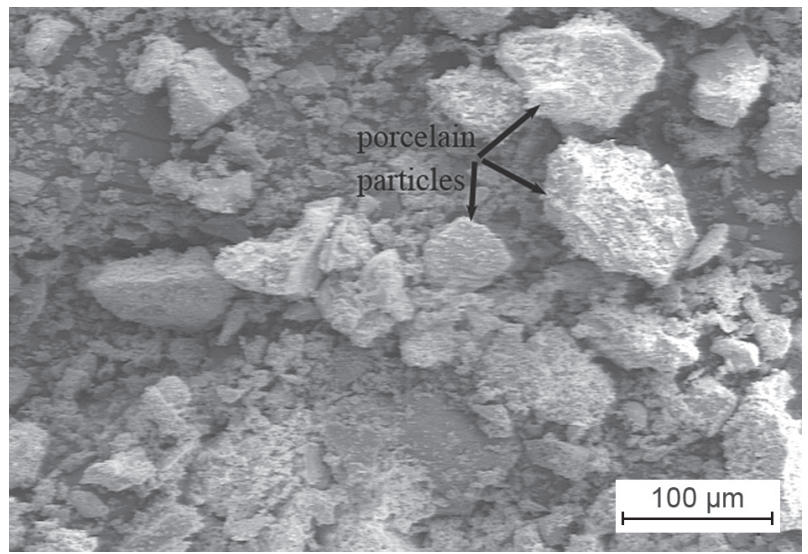

e) $1.5: 1$

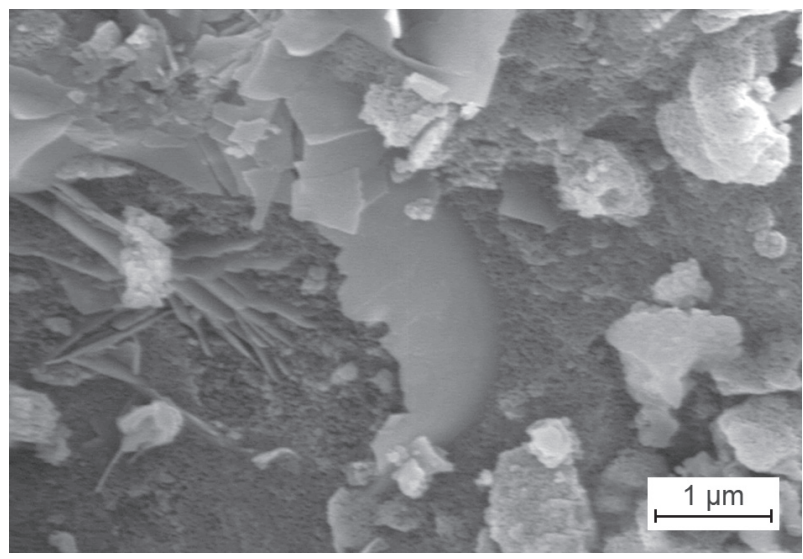

b) $1: 1$

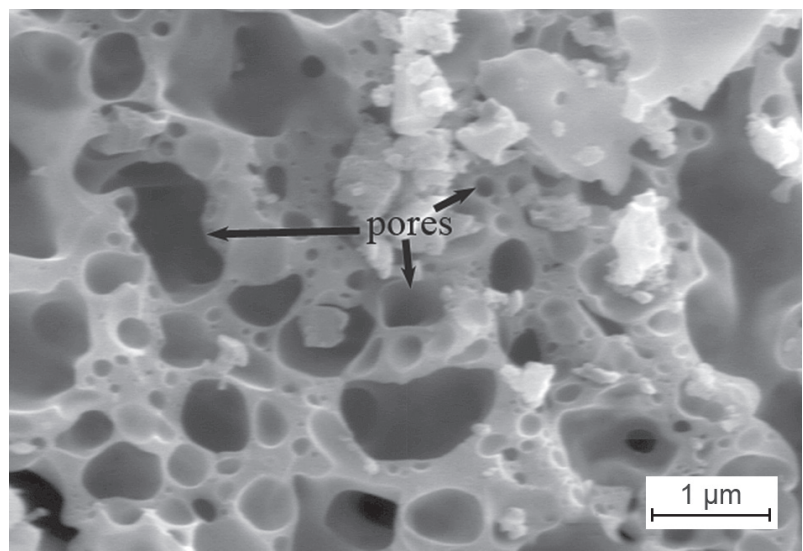

d) $1.25: 1$

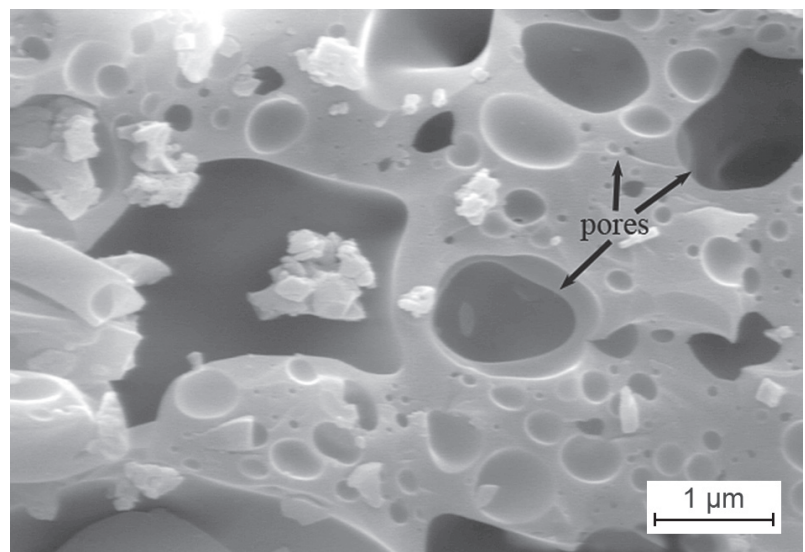

f) $1.5: 1$

Figure 4. The SEM microphotographs of the titanium body porcelains ignited at $500{ }^{\circ} \mathrm{C}$ with a fuel to nitrates ratio of: a,b) $\left.1: 1, \mathrm{c}, \mathrm{d}\right)$ 1.25:1 and e,f) 1.5:1. 


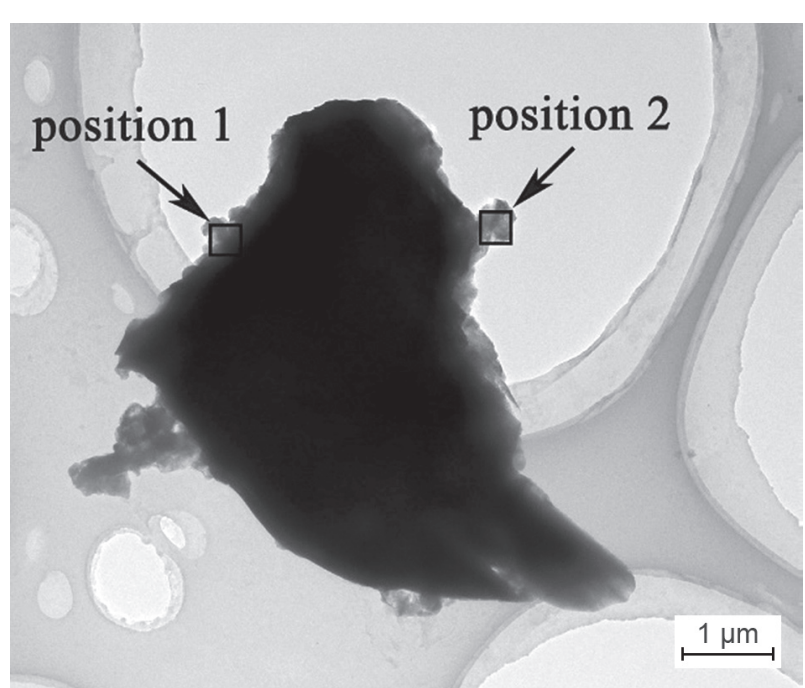

a)

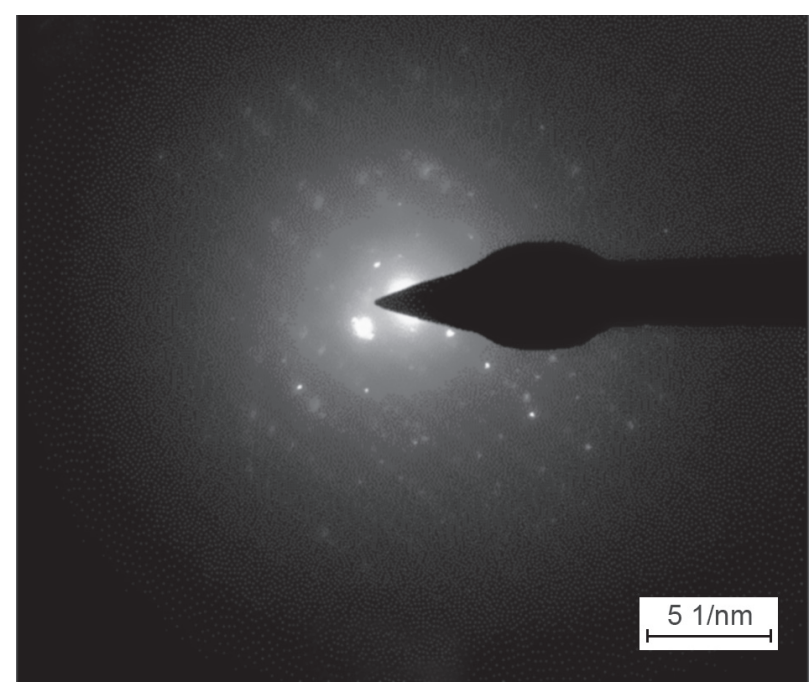

b)

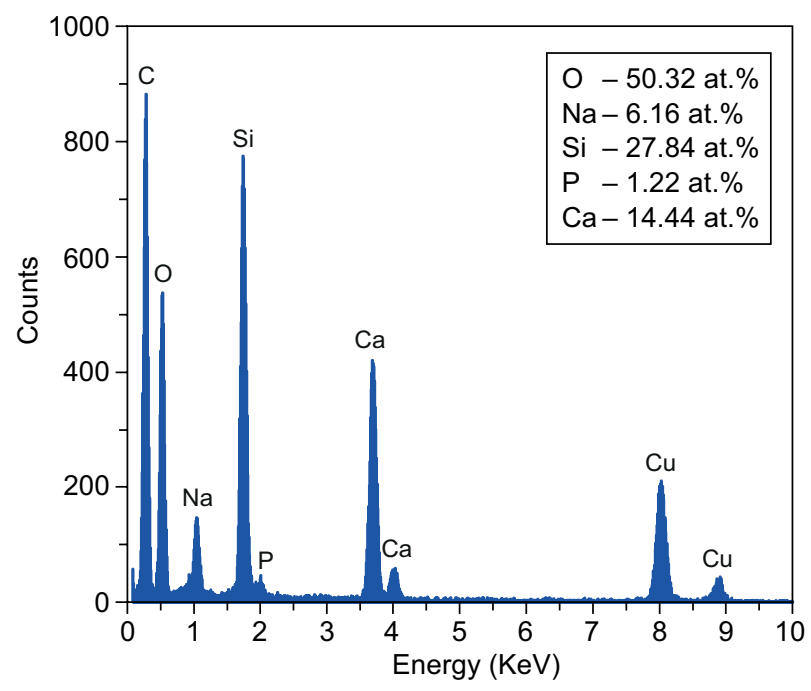

c)

Figure 5. The TEM (a), the selected area electron diffraction (SAED) (b) and the EDS photographs of the porcelain particles synthesised at $500{ }^{\circ} \mathrm{C}(\mathrm{c})$. porcelain particles was mainly amorphous, which was consistent with the XRD results in Figure 1. The TEM photograph in Figure 5c showed that the atomic composition of the main elements was $\mathrm{O} 50.32$ at. \%, $\mathrm{Na} 6.16$ at. $\%$, Si 27.84 at. \%, P 1.22 at. \% and $\mathrm{Ca}$ 14.44 at. $\%$, which converted to a weight composition of $\mathrm{Na}_{2} \mathrm{O} 8.59$ wt. $\%, \mathrm{SiO}_{2} 44.04$ wt. $\%, \mathrm{P}_{2} \mathrm{O}_{5} 3.90$ wt. $\%$ and $\mathrm{CaO} 43.48$ wt. \%. It was not completely consistent with the designing composition of the porcelain and we could see that the element Ca segregated on the surface of the powders. During the sol-gel combustion processing of the porcelain, phase separation was generated because of the high content of the alkali metal and alkaline earth metal oxide. This accounted for the composition inconsistence with the design.

Figure 6 shows the SEM photographs of the porcelain coatings microwave fused on Ti at: a), b) $700{ }^{\circ} \mathrm{C}$, c), d) $750{ }^{\circ} \mathrm{C}$. In Figures $6 \mathrm{a}, \mathrm{b}$, the pores in the coating are connected to each other, which revealed that the sintering temperature of $700{ }^{\circ} \mathrm{C}$ is not high enough to form a dense continuous network structure of the glass. While in Figures 6c and d, there are rarely pores on the surface of coating, and the coating was sintered to a dense homogeneous vitreous structure. After the temperature was increased by $50{ }^{\circ} \mathrm{C}$, the micro-structure of the coating changes significantly, from a porous structure into a dense structure.

Compared with conventional sintering, the densification process can be promoted because the heat flow in the microwave sintering comes from the interior of the particles and the higher diffusion coefficient can be obtained in the microwave electromagnetic field [11]. The continuous changes of dipoles in the materials can produce strong vibration and friction, therefore, promoting atomic diffusion, improving densification and quickening the chemical reaction [11].

Figure 7 shows the SEM and EDS element line scanning photographs of the cross-section of the Tiporcelain. Figure 7a shows that there were no obvious micro-cracks on the interface and the porcelain coating closely bonded to the Ti surface. The EDS element line scanning photograph in Fig $7 \mathrm{~b}$ indicated the element diffusion of $\mathrm{Ti}$ to the porcelain layer and $\mathrm{Si}$ to the $\mathrm{Ti}$ matrix. The thickness of the diffusion layer was about $10 \mu \mathrm{m}$. The microwave promoted atomic diffusion and improved the chemical reaction between the Tiporcelain, which would lead to the good bonding strength between Ti and the porcelain.

\section{CONCLUSIONS}

The amorphous body porcelains synthesised by the sol-gel combustion method were microwave fused on the Ti surface. A higher ratio of fuel to nitrates (1.25:1 and 1.5:1) and igniting temperature of $500{ }^{\circ} \mathrm{C}$ were employed to completely reduce the nitrates. When the igniting 


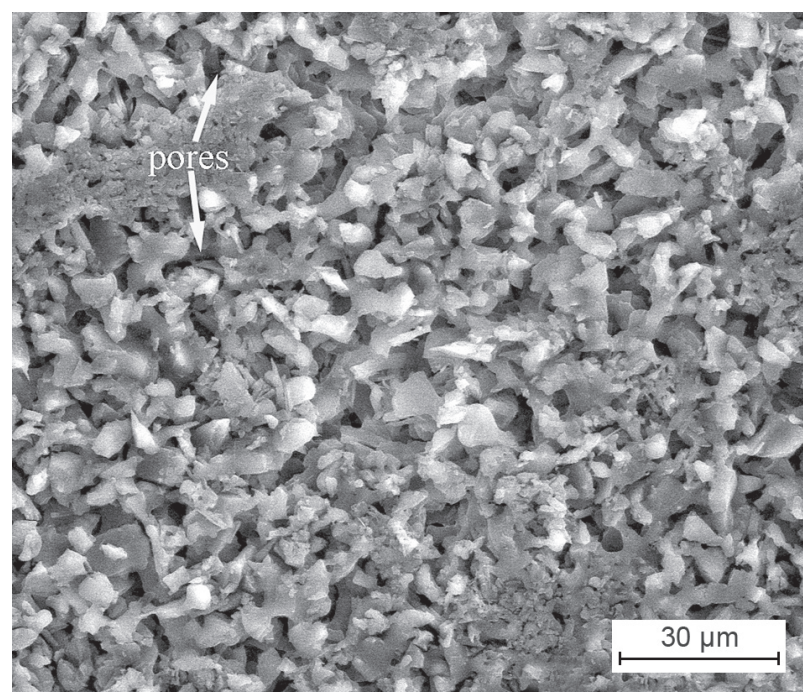

a) $700{ }^{\circ} \mathrm{C}$

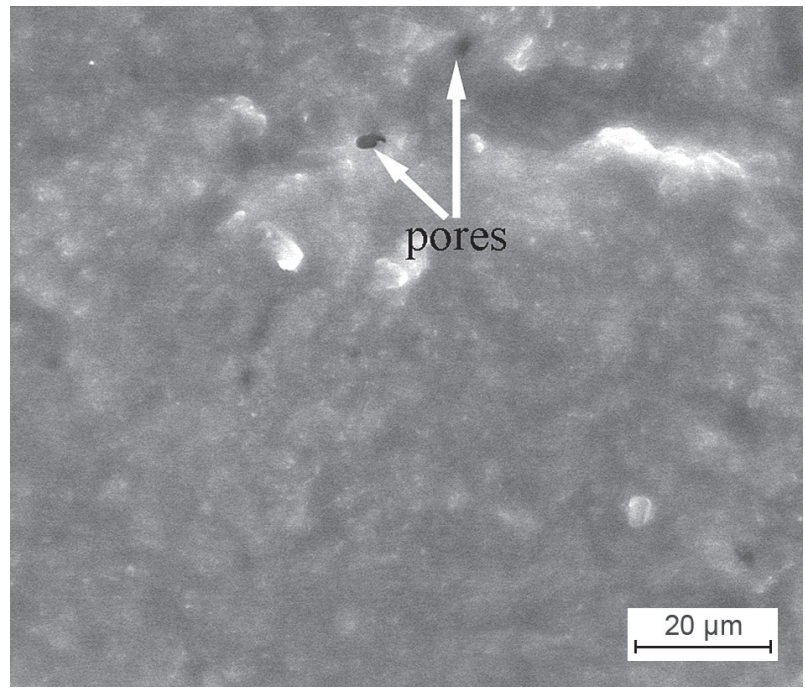

c) $750{ }^{\circ} \mathrm{C}$

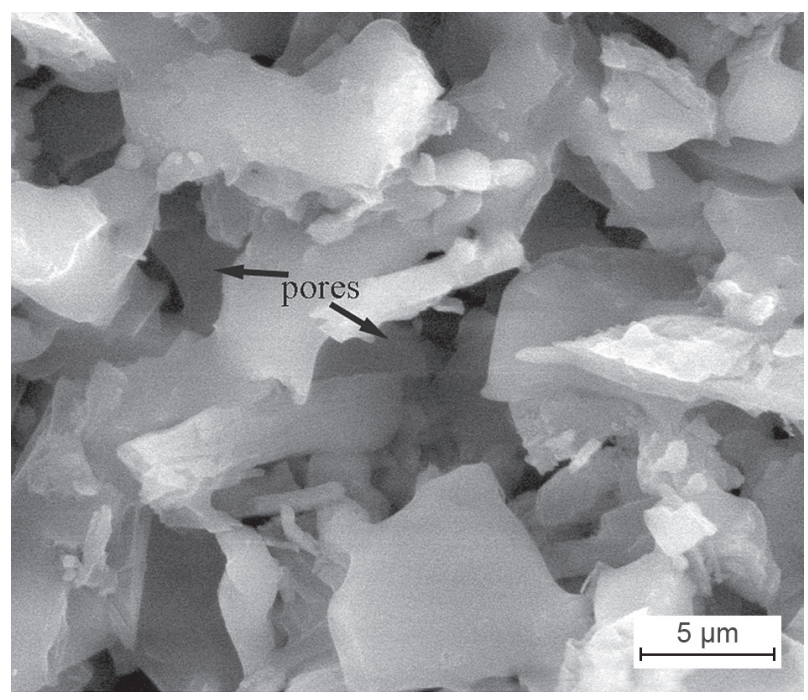

b) $700{ }^{\circ} \mathrm{C}$

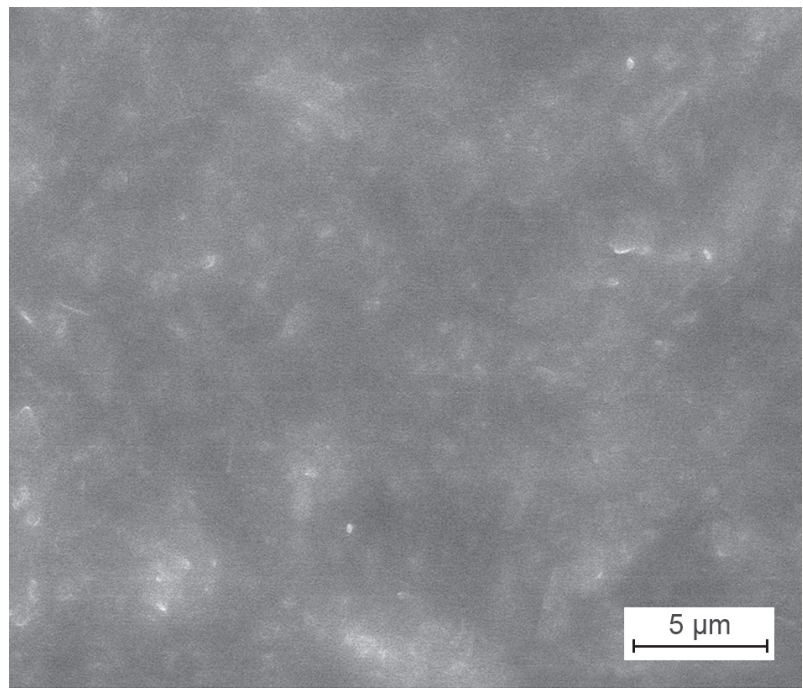

d) $750{ }^{\circ} \mathrm{C}$

Figure 6. The SEM photographs of the porcelain coatings microwave fused on Ti at: a), b) $700{ }^{\circ} \mathrm{C}$; c), d) $750{ }^{\circ} \mathrm{C}$.

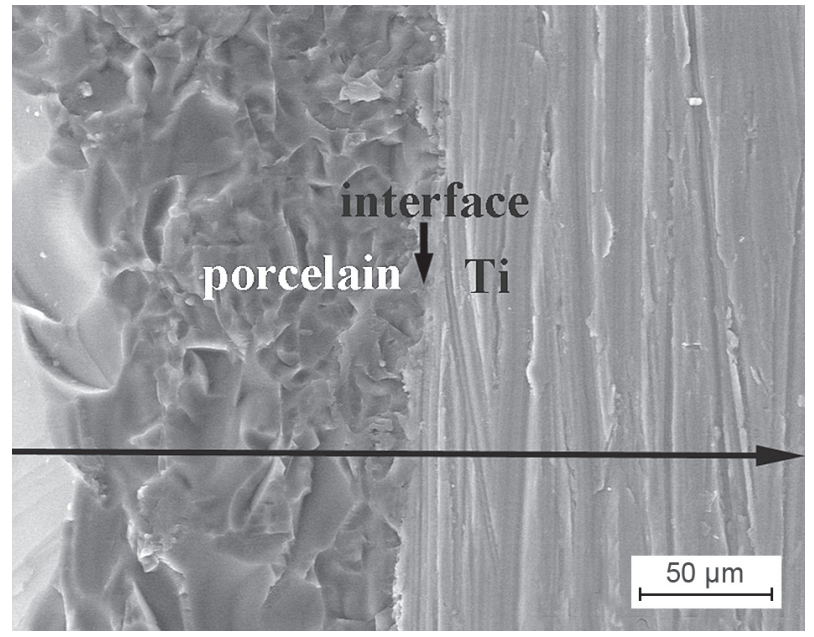

a) SEM

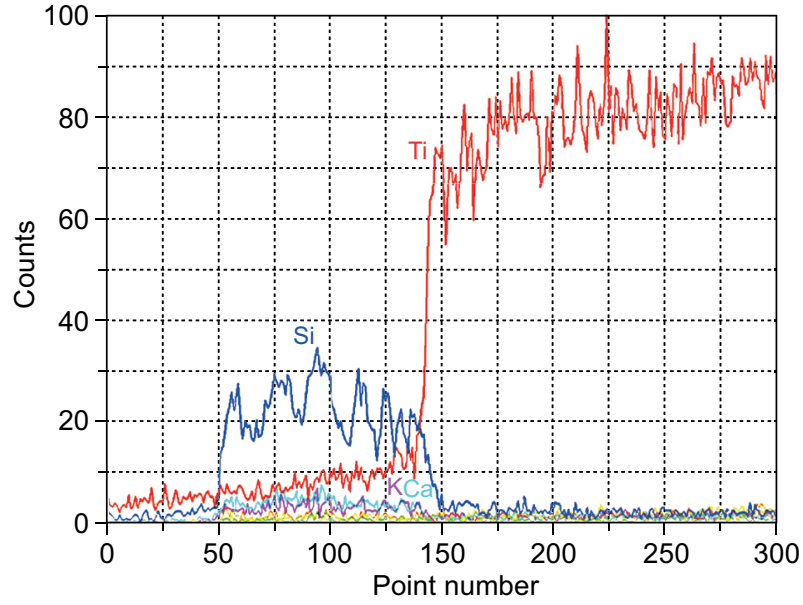

b) EDS

Figure 7. The SEM (a) and EDS element line scanning (b) photographs of the cross-section of the Ti-porcelain synthesised by microwave fusion at $750{ }^{\circ} \mathrm{C}$. 
temperature was elevated to 500 and $600{ }^{\circ} \mathrm{C}$ or higher, along with when the fuel to nitrates ratio increased from $1: 1$ to $1.5: 1$, the size and quantity of the pores slightly increased. The microwave promoted atomic diffusion and improved the chemical reaction between the Tiporcelain, which leads to the good bonding strength between $\mathrm{Ti}$ and the porcelain.

\section{Acknowledgements}

This research was sponsored by the Fundamental Research Funds for the Central Universities (Talent Cultivation Project).

\section{REFERENCES}

1. Xue B., Guo L., Chen X., Fan Y., Ren X., Li B., Ling Y., Qiang Y. (2017): Electrophoretic deposition and laser cladding of bioglass coating on Ti. Journal of Alloys and Compounds, 710, 663-669. Doi: 10.1016/j.jallcom.2017. 03.209

2. Cai Z., Bunce N., Nunn M. E., Okabe T. (2001): Porcelain adherence to dental cast CP titanium: effects of surface modifications. Biomaterials, 22(9), 979-986. Doi: 10.1016/ S0142-9612(00)00263-5

3. Guo L., Chen X., Liu X., Feng W., Li B., Lin C., Tao X., Qiang Y. (2016): Surface modifications and Nanocomposite coatings to improve the bonding strength of titanium-porcelain. Materials Science and Engineering: C, 61, 143-148. Doi: 10.1016/j.msec.2015.12.030

4. Polymeris G. S., Giannoulatou V., Kyriakidou A., Sfampa I. K., Theodorou G. S. et al. (2017): Bioactivity characterization of 45S5 bioglass using TL, OSL and EPR: comparison with the case of $58 \mathrm{~S}$ sol-gel bioactive glass. Materials Science and Engineering: C, 70, 673-680. Doi: 10.1016/j.msec.2016.09.051
5. Guo L., Feng W., Liu X., Lin C., Li B., Qiang Y. (2015): Sol-gel synthesis of antibacterial hybrid coatings on titanium. Materials Letters, 160, 448-451. Doi: 10.1016/j. matlet.2015.08.027

6. Chen X., Guo L., Xue B., Lin C., Qiang Y. (2017): Sol-gel synthesis and laser fusion of Ti-bonding porcelain hybrid coatings on titanium. Journal of Sol-Gel Science and Technology, 82(2), 581-585. Doi: 10.1007/s10971-017-4327-x

7. Zheng K., Solodovnyk A., Li W., Goudouri O. M., Stähli C., Nazhat S. N., Boccaccini A. R. (2015): Aging time and temperature effects on the structure and bioactivity of gel-derived 45S5 glass-ceramics. Journal of the American Ceramic Society, 98(1), 30-38. Doi: 10.1111/jace.13258

8. Choudhary R., Vecstaudza J., Krishnamurithy G., Raghavendran H. R. B., Murali M. R. et al. (2016): In-vitro bioactivity, biocompatibility and dissolution studies of diopside prepared from biowaste by using sol-gel combustion method. Materials Science and Engineering: C, 68, 89-100. Doi: 10.1016/j.msec.2016.04.110

9. Choudhary R., Koppala S., Swamiappan S. (2015): Bioactivity studies of calcium magnesium silicate prepared from eggshell waste by sol-gel combustion synthesis. Journal of Asian Ceramic Societies, 3(2), 173-177. Doi: 10.1016/j.jascer.2015.01.002

10. Lin L., Zhang L., Wang J., Xie K., Yang X., et al. (2014): Low-temperature sintering of 45S5 Bioglass ${ }^{\circledR}$-based glass ceramics: Effect of biphasic mixing approach on the mechanical and biological properties. Materials Letters, 126, 154-158. Doi: 10.1016/j.matlet.2014.04.028

11. Medeiros F. D. S. C., Menezes R. R., Neves G. A., de Lima Santana L. N., Ferreira H. S., de Lima D. S. G., de Lima S. J. G. (2015) : Microwave-assisted sintering of dental porcelains. Ceramics International, 41(6), 7501-7510. Doi: 10.1016/j.ceramint.2015.02.072

12. Chen X., Guo L., Liu X., Feng W., Li B., Tao X., Qiang Y. (2017): Effect of laser parameters on the microstructure of bonding porcelain layer fused on titanium. Optical Materials, 71, 136-140. Doi: 10.1016/j.optmat.2017.01.046 